\title{
DivUlgaÇÃo CIENTÍficA, ENSINO DE FÍsicA E A CIÊNCIA ENVOLVIDA NO ESTUDO DE SATÉLITES
}

SCIENTIFIC OUTREACH, PHYSICS TEACHING AND THE SCIENCE INVOLVED IN THE STUDY OF SATELLITES

DIFUSIÓN CIENTÍFICA, ENSEÑANZA DE LA FÍSICA Y LA CIENCIA INVOLUCRADA EN ESTUDIO SATÉLITE

\section{Yeté Abunã Marques \\ Labarca \\ (iD) 9}

Licenciando em Física pelo IFSP-

Caraguatatuba

yete.abuna@gmail.com

\section{Ricardo Roberto Plaza Teixeira

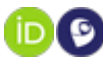

Doutor em Física pela USP (1996)

Docente do IFSP-Caraguatatuba na categoria de professor titular rteixeira@ifsp.edu.br

\begin{abstract}
Resumo
Este artigo tem como objetivo analisar atividades de divulgação científica que foram realizadas sobre o estudo dos satélites e conhecimentos de física aeroespacial e de tecnologia. As apresentações feitas envolveram tópicos de História da Ciência e da Tecnologia, de modo a tornar mais compreensível o processo de desenvolvimento científico. Essas atividades foram planejadas tendo como eixo temático a ciência e a história envolvida na corrida espacial entre Estados Unidos e União Soviética, no contexto da guerra fria, no século XX, bem como a importância das pesquisas realizadas no setor aeroespacial para o desenvolvimento econômico e social das nações nos dias de hoje. Em algumas apresentações foram coletados dados por questionários que foram elaborados para poder compreender os impactos educacionais das ações implementadas. Os resultados das atividades realizadas mostram algumas possibilidades para incentivar jovens estudantes para o estudo de áreas como física, matemática, computação, astronomia e astronáutica.
\end{abstract}

Palavras-chave: Educação Científica. História da Ciência. Física Espacial. Desenvolvimento Tecnológico.

Recebido em: 21 de março de 2021.

Aprovado em: 2 de junho de 2021.

Como citar esse artigo (ABNT):

LABARCA, Yeté Abunã Marques; TEIXEIRA, Ricardo Roberto Plaza. Divulgação científica, ensino de física e a ciência envolvida no estudo de satélites. Revista Prática Docente, v. 6, n. 2, e037, 2021.

http://doi.org/10.23926/RPD.2021.v6.n2.e037.id1054 


\section{Abstract}

This article aims to analyze scientific dissemination activities that have been carried out on the study of satellites and related knowledge of aerospace physics and technology. The presentations made involved topics in the History of Science and Technology, to make the process of scientific development more understandable. These activities were planned based on the science and the history involved in the space race between the United States and the Soviet Union, in the context of the cold war, in the twentieth century, as well as the importance of the research conducted in the aerospace sector for the economic and social development of nations nowadays. In some presentations, data were collected through questionnaires designed to understand the educational impacts of the actions implemented. The results of the activities allow us to visualize some possibilities to encourage young students to study areas such as physics, mathematics, computation, astronomy and astronautics. Keywords: Scientific Education. History of Science. Space Physics. Technological Development.

\section{Resumen}

Este artículo tiene como objetivo analizar las actividades de divulgación científica que se llevaron a cabo sobre el estudio de los satélites y el conocimiento de la física aeroespacial y tecnología. Las presentaciones realizadas involucraron temas de la Historia de la Ciencia y la Tecnología con el fin de hacer más comprensible el proceso de desarrollo científico. Estas actividades se planificaron en base a la ciencia y la historia involucradas en la carrera espacial entre los Estados Unidos y la Unión Soviética, en el contexto de la guerra fría en el siglo XX, así como la importancia de la investigación en el sector aeroespacial para el desarrollo económico y social de las naciones de hoy. En algunas presentaciones se recolectaron datos a través de cuestionarios que fueron diseñados para poder comprender los impactos educativos de las acciones implementadas. Los resultados de las actividades realizadas muestran algunas posibilidades para animar a los jóvenes estudiantes a estudiar áreas como la física, las matemáticas, la informática, la astronomía y la astronáutica.

Palabras Clave: Enseñanza de las ciencias. Historia de la ciencia. Física espacial. Desarrollo tecnológico. 


\section{INTRODUÇÃo}

Este trabalho objetiva analisar ações de divulgação da ciência envolvendo o estudo de satélites, foguetes e sondas, bem como conhecimentos tanto sobre a história da corrida espacial entre Estados Unidos e União Soviética, quanto sobre os desdobramentos econômicos das pesquisas no setor aeroespacial. Durante as cinco apresentações realizadas no segundo semestre de 2019, verificamos que assuntos relacionados ao estudo da ciência e da tecnologia espacial atraem o interesse de muitos estudantes da educação básica: esta temática pode ser utilizada com finalidades educacionais, como recurso motivador para a aprendizagem de conceitos fundamentais de diversas áreas científicas, em particular da física. Esta é uma pesquisa na qual os pesquisadores e alunos interagiram de um modo colaborativo, o que provocou uma proximidade com a realidade local das escolas nas quais as atividades aconteceram; a análise dos resultados teve um caráter sobretudo qualitativo, como acontece com diversos outros trabalhos de investigação na área da divulgação científica, com o intuito de investigar diferentes aspectos do processo de aprendizagem acerca dos temas tratados (OLIVEIRA, 2015).

Após essa breve introdução, alguns conteúdos históricos e científicos relevantes em termos educacionais sobre essas temáticas são abordados em detalhes, inclusive com o fornecimento de links para acessar recursos didáticos que podem ser valiosos para o processo de ensino e aprendizagem. Em seguida, são examinadas as referências teóricas da área do ensino de ciências e da divulgação científica que alicerçaram o trabalho realizado. Na sequência, são descritas as atividades de divulgação implementadas e são discutidos os resultados obtidos, em particular os impactos das ações realizadas e as concepções dos alunos acerca dos temas abordados nelas. Finalmente, nas considerações finais é feita uma sistematização panorâmica do trabalho feito, com a apresentação de algumas possíveis conclusões e sugestões.

\section{A HISTÓRIA DA CIÊNCIA ESPACIAL}

Atualmente milhares de satélites orbitam a Terra em uma grande variedade de missões específicas: a história desses objetos remonta ao dia 4 de outubro de 1957, quando ocorreu o lançamento pelos soviéticos do primeiro satélite artificial, o Sputnik 1, tornando realidade o início do processo de conquista do espaço sideral pela humanidade (CARLEIAL, 2009).

A União Soviética (URSS) conseguiu realizar esta proeza ao colocar uma esfera metálica de massa igual a $83,6 \mathrm{~kg}$ e diâmetro de $58 \mathrm{~cm}$ para orbitar a Terra, com dois pares de antenas com comprimento entre 2,4 e 2,9 m. Por 22 dias, até se esgotar a energia da bateria do transmissor, foram emitidos sinais de rádio na faixa entre $20 \mathrm{MHz}$ e $40 \mathrm{MHz}$ que podiam ser 
escutadas por qualquer radioamador e que permitiram compreender e caracterizar o modo como ocorre a transmissão de ondas de rádio na ionosfera. Em 4 de janeiro de 1958, o Sputnik reentrou na atmosfera e pegou fogo, após realizar cerca de 1400 órbitas em torno da Terra.

Diversos arquivos com documentos e informações históricas sobre o Sputnik podem ser encontrados no site da Divisão de História da NASA ("Sputnik and the Dawn of the Space Age" ou, traduzido em português, "Sputnik e o Alvorecer da Era espacial”). O material histórico disponibilizado sobre o Sputnik no site da NASA é bastante diversificado, contando, por exemplo, com livros, documentos históricos, fotografias, imagens, uma linha cronológica temporal ("timeline") com os eventos que ocorreram durante o início da corrida espacial entre os EUA e a União Soviética e até mesmo com o áudio gravado dos "beeps" que eram enviados por este satélite ${ }^{2}$.

O foguete de lançamento que partiu em 1957 da base de Baikonur (atualmente situada na República do Cazaquistão que na época fazia parte da União Soviética) tinha 19 metros de altura e 137 toneladas: somente o combustível constituído de oxigênio líquido e querosene tinha uma massa de 126 toneladas, ou seja, mais de $90 \%$ da massa do foguete. A órbita, com período de cerca de 96 minutos, era elíptica com altitude variando entre 230 e $950 \mathrm{~km}$; o plano da órbita possuía uma inclinação de aproximadamente $65^{\circ}$ com o Equador terrestre (WINTER; PRADO, 2007). Após a URSS ter posto o primeiro satélite em órbita, eles foram além, cerca de um mês depois: em 3 de novembro de 1957, eles lançaram ao espaço o Sputnik 2, com massa de 542,3 kg e contendo a cadela Laika (GARCIA, 2017).

A complacência com que os investimentos em ciência foram encarados nos Estados Unidos, após o final da Segunda Guerra Mundial até os anos 1950, teve um fim com o lançamento do Sputnik e a percepção de que os soviéticos estavam vencendo a corrida científica e tecnológica (NEAL; SMITH; MCCORMICK, 2008). A opinião pública dos EUA constatou imediatamente que a URSS estava se desenvolvendo e produzindo tecnologias suficientes para lançar objetos a longas distâncias, o que tinha implicações militares (DIVINE, 1993).

Em 1958, os EUA entraram na corrida espacial, lançando o Explorer 1 (HOWELL, 2017). Como consequência do abalo político propiciado pela ideia de que a URSS estava na frente na corrida espacial, os EUA fundaram a NASA ("National Aeronautics and Space Administration" ou "Administração Nacional da Aeronáutica e Espaço"), em 1 de outubro de

\footnotetext{
${ }^{1}$ Disponível em: https://history.nasa.gov/sputnik.html

${ }^{2}$ A gravação está disponível em: https://www.nasa.gov/mp3/191322main_sputnik-beep.mp3
} 
1958, e deram início ao PSSC ("Physical Science Study Committee” ou Comitê de Estudo de Ciências Físicas), um projeto para melhorar o ensino de física nas escolas de ensino médio do país (GOMES; PIASSI, 2014).

Em 1959, a URSS deu um passo mais à frente e criou um programa de exploração espacial chamado Luna, para exploração da Lua. Em seu primeiro lançamento, ocorrido em 2 de janeiro de 1959, a missão Luna 1 chegou a $6000 \mathrm{~km}$ de altitude da Lua (WILLIAMS, 2019). A missão Luna 2, lançada em 12 de setembro de 1959, foi uma espécie de "tiro certeiro", tornando-se o primeiro objeto produzido pelo ser humano a atingir a superfície da Lua.

No início da década de 60, com mais de 44 satélites em volta da Terra, a URSS deu outro passo. A bordo da nave Vostok 1, em 12 de abril de 1961, o cosmonauta soviético Yuri A. Gagarin (1934-1968) foi o primeiro homem a viajar pelo espaço (CARLEIAL, 2009), em um voo espacial que durou 1 hora e 48 minutos. Com as notícias dos soviéticos sobre o primeiro homem no espaço, os EUA também lançaram no mês seguinte uma pessoa ao espaço. Em 5 de maio de 1961, o astronauta estadunidense Alan Shepard (1923-1998), na nave Mercury, subiu $200 \mathrm{~km}$ de altitude, porém, seu voo durou 15 minutos, o que frustrou alguns devido ao tempo curto de permanência no espaço (MAY, 2017). No mesmo mês que Shepard foi ao espaço, o presidente estadunidense da época, John F. Kennedy, fez seu célebre discurso no Congresso dos EUA, no qual afirmou que até o final dos anos 1960 os EUA iriam colocar um homem na Lua (CHAIKIN, 2019): "I believe this nation should commit itself, before this decade is out, to landing a man on the moon and returning him safely to the Earth. No single space project in this period will be more impressive to mankind, or more important in the long-range exploration of space; and none will be so difficult or expensive to accomplish." ${ }^{3}$. Em tradução livre: "Eu acredito que esta nação deve se comprometer, antes que esta década acabe, em pousar um homem na Lua e devolvê-lo para a Terra em segurança. Nenhum projeto espacial isolado neste período será mais impressionante para a humanidade ou mais importante na exploração do espaço de longo alcance; e nenhum será tão difícil ou caro de realizar.”.

Como consequência da corrida espacial, em 1969, os EUA cumpriram o compromisso assumido no discurso de Kennedy e enviaram 3 homens em uma viagem à Lua, a bordo da Saturno V, nave da missão Apollo 11: Neil Alden Armstrong (1930-2012) e Edwin Eugene Aldrin Jr., mais conhecido como Buzz Aldrin (1930-) fizeram uma alunissagem com o Módulo

\footnotetext{
${ }^{3}$ Disponível em: https://history.nasa.gov/SP-350/ch-2-1.html 
Lunar e caminharam por duas horas na superfície da Lua, enquanto Michael Collins (1930-) permaneceu na órbita lunar no Módulo de Comando e Serviço.

Os motivos desta reviravolta, com os Estados Unidos retomando a liderança da corrida espacial, tornaram-se objeto de muitas discussões científicas, tecnológicas, históricas, econômicas e políticas. De qualquer modo, a corrida espacial entre EUA e URSS, entre as décadas de 1950 e 1980, marcou profundamente este período de guerra fria, entre as duas nações militarmente mais poderosas do planeta. Essa foi uma época em que, paradoxalmente, uma guerra frontal e aberta entre as duas superpotências era improvável, mesmo que cada lado tivesse pontos de vistas bastante antagônicos nos campos políticos e econômicos, porque existia o temor de que o enfrentamento direto entre as duas nações poderia destruir o planeta por completo, pela eclosão de uma guerra nuclear (PESSOA FILHO, 2005).

Em termos contemporâneos, um levantamento feito em 31 de março de 2020, indicou a existência de 5.774 satélites em órbita em torno da Terra, de acordo com o "United Nations Office for Outer Space Affairs" (UNOOSA) ou "Escritório para Assuntos do Espaço Exterior das Nações Unidas"; 580 objetos foram lançados ao espaço em 2019, a maior taxa anual de lançamentos da história. De 4 de outubro de 1957 até 31 de março de 2020, 9.456 objetos foram lançados ao espaço exterior.

Segundo a "Union of Concerned Scientists" (UCS) (em tradução livre, "Sindicato dos Cientistas Preocupados"), que mantém um registro dos satélites operacionais, no final de março de 2020, 2.666 satélites (ou seja, 46\% dos objetos em órbita em torno da Terra) ainda estavam ativos (LAVANDER, 2020). O resto virou "lixo espacial", um problema que vem crescendo com o tempo: portanto, há mais de 3.100 pedaços de metal voando ao redor da Terra a milhares de quilômetros por hora sem fazer absolutamente nada.

As cinco nações com maior número de satélites operacionais são: Estados Unidos, China, Rússia, Reino Unido e Japão. Dos satélites que estavam operacionais ao final de março de 2020: 1.211 eram satélites de comunicação, 884 eram satélites de observação da Terra, 312 eram satélites de desenvolvimento de tecnologias, 148 eram satélites de navegação ou posicionamento, 93 eram satélites voltados para a pesquisa em ciência espacial e 18 eram satélites voltados para a pesquisa nas ciências da Terra, sendo que em alguns casos existiam satélites com múltiplas finalidades. A empresa SpaceX, fundada pelo empresário estadunidense Elon Musk, tem controle sobre uma grande quantidade de satélites: o empreendimento

\footnotetext{
${ }^{4}$ Disponível em: https://www.unoosa.org/ 
"Starlink" contava com uma constelação de 358 satélites para comunicação por internet. Ao olhar com atenção o céu noturno, é possível ver alguns satélites artificiais da Terra a olho nu, bem como a própria Estação Espacial Internacional (que está a uma altitude de aproximadamente $400 \mathrm{~km}$ ): então, quando se vê um objeto brilhante movendo-se no céu, ele provavelmente pode ser um satélite!

Cerca de 1.918 satélites estão em uma órbita terrestre baixa, na qual a altitude é menor que $2.000 \mathrm{~km}$. Os satélites com mais baixa altitude são aqueles que estão a cerca de $250 \mathrm{~km}$ acima da superfície terrestre, os quais geralmente são satélites governamentais, militares ou de observação que tiram fotos da superfície terrestre. Aproximadamente 1.454 satélites estão listados como tendo usuários comerciais, 599 têm usuários governamentais, 477 têm usuários militares e 136 têm usuários civis.

Cerca de 5\% (137) dos satélites estão em uma órbita terrestre com altitudes médias de cerca de $20.000 \mathrm{~km}$ acima da Terra, enquanto 57 satélites estão em órbitas elípticas, em alguns momentos se aproximando e em outros momentos se afastando consideravelmente da Terra. Um total de 554 satélites estão em órbitas equatoriais geossíncronas ou geoestacionárias em uma altitude de cerca de $36.000 \mathrm{~km}$ (pouco menos que 6 vezes o raio da Terra): se pudéssemos ver esses satélites da superfície terrestre, eles pareceriam estar imóveis no céu. O fato de eles permanecerem sempre sobre uma mesma área geográfica significa que eles fornecem a plataforma perfeita para telecomunicações, radiodifusão ou observações meteorológicas naquela área (CAIN, 2013). Há também satélites, construídos pelo ser humano, que estão orbitando outros corpos do Sistema Solar como a Lua, o próprio Sol e os planetas.

Atualmente, a confecção de satélites de pequeno porte permite a reutilização de subsistemas e propicia uma cultura de inovação: os satélites pequenos são úteis não apenas para objetivos técnicos, como também para desenvolvimentos científicos em meteorologia, sensoriamento, manejo florestal, planejamento urbano, agricultura e preservação ambiental. Um bom exemplo de um trabalho com satélites de pequeno porte em escolas da educação básica é o "UBATUBASAT", desenvolvido por alunos e professores da Escola Municipal Presidente Tancredo de Almeida Neves da cidade de Ubatuba que fica localizada no litoral norte paulista (TIKAMI; MOURA; SANTOS, 2017). Há inclusive um documentário de boa qualidade produzido a respeito do "Ubatubasat"5 (intitulado "Projeto Ubatubasat - Uma jornada do conhecimento"). Os desafios enfrentados pelo projeto "Ubatubasat" motivaram reflexões

\footnotetext{
${ }^{5}$ Disponível em https://www.youtube.com/watch?v=VgLM10KKKz8
} 
acerca da importância do desenvolvimento de conhecimentos nesta área do conhecimento, no âmbito desta pesquisa, até pelo fato de este projeto estar situado em Ubatuba, na região geográfica em que ocorreu essa pesquisa.

O Brasil é um país com um grande potencial de desenvolvimento de uma indústria aeroespacial pujante, o que pode colaborar com a prosperidade social e econômica de sua população e trazer vantagens estratégicas: no setor espacial, o país consegue produzir satélites, foguetes de sondagem e veículos lançadores (COSTA, 2013). Apesar do desenvolvimento tecnológico espacial, liderado pela Agência Espacial Brasileira (AEB), um elemento muito relevante das realizações nacionais (REIS, 2008), é fundamental investir na melhoria dos recursos humanos e uma forma disso ocorrer é por meio de projetos didáticos, especialmente junto a estudantes da educação básica, que incentivem a curiosidade, a investigação e o desenvolvimento de conhecimentos relacionados às ciências espaciais.

Há muitos vídeos de curta duração bem fundamentados e de boa qualidade sobre física espacial e o estudo de satélites disponíveis em plataformas de armazenamento de vídeos como o YouTube e que podem ser utilizados em atividades educacionais com sucesso como ferramentas de auxílio para a aprendizagem. Três exemplos serão citados aqui, mas há diversos outros: o vídeo intitulado "Tirania da Equação do Foguete" com duração de 8 minutos e 52 segundos, produzido pelo canal "Ciência Todo Dia" do YouTube; o vídeo de animação intitulado "Quem venceu a corrida espacial? - Jeff Steers" (narrado em inglês e com legenda disponível em português) com duração de 4 minutos e 46 segundos, produzido pelo canal TEDEd do YouTube 7 ; o vídeo intitulado "Apollo 11's journey to the moon - annotation", cuja tradução é "A jornada da Apollo 11 até a Lua - anotação" (narrado em inglês e com a possibilidade de a legenda em português ser ativada) com duração de 5 minutos e 13 segundos, produzido pelo canal VOX do YouTube . $^{8}$

$\mathrm{O}$ site da Agência Espacial Brasileira $(\mathrm{AEB})^{9}$ disponibiliza também a qualquer interessado um rico repositório de arquivos acerca da temática espacial, com apresentações, vídeos e outros materiais que podem ser muito úteis na realização de atividades de cunho didático. Estes recursos foram preparados por conferencistas e colaboradores para minicursos, cursos de extensão e cursos de capacitação de professores.

\footnotetext{
${ }^{6}$ Disponível em: https://www.youtube.com/watch?v=FuDMJixyuNA\&t=6s

${ }^{7}$ Disponível em: https://www.youtube.com/watch?v=FxpC-8f--xo

${ }^{8}$ Disponível em https://www.youtube.com/watch?v=OCjhCL2iqlQ\&t=4s

${ }^{9}$ Disponível em: http://aebescola.aeb.gov.br/index.php/repositorio/apresentacoes 


\section{DivUlgaÇão CIENTífICA}

Este trabalho parte de uma abordagem para a educação científica que promova a cidadania e enfatize os aspectos sociais do desenvolvimento científico, de modo a favorecer a apropriação pelos alunos de conhecimentos, valores e habilidades que os capacitem a compreender os assuntos envolvidos, tomar decisões responsáveis e agir buscando soluções naquilo que diga respeito a questões científicas que afetam a sociedade (SANTOS; MORTIMER, 2000). Em particular, um dos pressupostos é que a exploração de questões relacionadas com as controvérsias que ocorreram no passado e ocorrem no presente devido às implicações sociais da Ciência e da Tecnologia, ajuda a dar significado aos conteúdos científicos trabalhados no âmbito educacional e confere vida ao processo de aprendizagem, pois permite uma apropriação ativa do conhecimento científico pelos alunos (SILVA; CARVALHO, 2009): as dimensões éticas, sociais e econômicas da ciência colaboram significativamente para a compreensão das leis e conceitos científicos envolvidos, pois permitem dar uma narrativa para aquilo que é aprendido (HARARI, 2018).

Para a fundamentação deste trabalho, foi importante também a ideia de ciência cidadã (“citizen science") que pressupõe que pessoas sem especialização podem participar na análise e coleta de dados de pesquisa (ALBAGLI; CLINIO; RAYCHTOCK, 2014), o que possibilita que elas colaborem para o desenvolvimento tecno-científico, tornando a ciência mais acessível para todos. Portanto, nesta perspectiva, atividades de divulgação científica são importantes para ajudar a motivar mais cidadãos para que se apropriem do conhecimento científico construído pelo esforço coletivo humano e, para isso, os cientistas precisam ser mais abertos junto ao público (THE ROYAL SOCIETY, 2012).

Adicionalmente, um pressuposto assumido, foi o de que o uso de uma linguagem mais leve, simples e acessível, sem perder o sentido original, permite que a divulgação científica seja um meio de tradução de conceitos técnicos (ALBAGLI, 1996), ou seja, possibilita uma transposição da informação acadêmica para o público leigo, propiciando também uma compreensão de conceitos e princípios da ciência abordados, em prol da educação científica (MAGALHÃES; SILVA; GONÇALVES, 2017).

Assim sendo, essa pesquisa teve como objetivo principal analisar atividades de divulgação da ciência centradas principalmente nos aspectos científicos e históricos da corrida espacial entre Estados Unidos e União Soviética e nas consequências econômicas e sociais do desenvolvimento aeroespacial nos dias de hoje, tanto para despertar o interesse dos alunos para 
a pesquisa científica, quanto para tratar de aplicações da física clássica no estudo de satélites artificiais, foguetes e sondas espaciais. Para isto, foram realizadas em 2019, apresentações de divulgação científica a respeito destes temas junto a estudantes de ensino médio de 5 (cinco) escolas públicas situadas em três municípios do litoral norte do estado de São Paulo: Caraguatatuba, Ubatuba e São Sebastião.

Como embasamento para o planejamento e a estruturação das atividades foi feita uma revisão bibliográfica com um levantamento e a análise de artigos em revistas especializadas, trabalhos em congressos acadêmicos, livros, monografias de graduação, dissertações de mestrado e teses de doutorado sobre física aeroespacial e o estudo dos satélites, bem como textos para a fundamentação teórica em áreas como ensino de física, divulgação científica e história da ciência e da tecnologia.

Durante esta etapa foram estudados também trabalhos em áreas adjacentes como astronomia, matemática, eletrônica e programação de computadores. Os trabalhos estudados foram obtidos sobretudo por meios virtuais como a "Google Scholar" ou "Google Acadêmico"10 e a SciELO - "Scientific Eletronic Library Online" ou "Biblioteca Científica Eletrônica Online"11. Foram também usadas, durante esta revisão bibliográfica, obras tanto da Biblioteca do IFSP-Caraguatatuba, quanto da Biblioteca Virtual Pearson, a qual estudantes e servidores do IFSP têm acesso.

\section{ATIVIDADES DE DIVULGaÇÃo CIENTÍFICA REALIZADAS}

As apresentações de divulgação científica realizadas (na forma de palestras interativas), no transcorrer da pesquisa que redundou neste presente artigo, tiveram uma duração média de cerca de 30 minutos e utilizaram recursos como imagens, vídeos científicos de curta duração e simulações para a apresentação dos conceitos científicos em foco. Elas versaram basicamente sobre física aeroespacial e satélites artificiais e foram realizadas junto a grupos com entre $30 \mathrm{e}$ 40 alunos de ensino médio em cada uma de cinco escolas públicas situadas no litoral norte de São Paulo (que serão numeradas com algarismos romanos, de I a V), entre agosto e outubro de 2019. A abordagem utilizada durante estas atividades envolveu questões científicas e históricas relacionadas à corrida espacial entre Estados Unidos e União Soviética, durante a guerra fria, na segunda metade do século XX; também foi discutida a importância do setor aeroespacial para o desenvolvimento das nações nos dias de hoje. Este enfoque permitiu adotar uma

\footnotetext{
${ }^{10}$ Disponível em: https://scholar.google.com.br/

${ }^{11}$ Disponível em: https://scielo.org/ 
perspectiva interdisciplinar nas apresentações, sobretudo pela aproximação realizada entre as disciplinas de física e de história, o que possibilitou despertar a curiosidade de estudantes com diferentes interesses disciplinares, atingindo tanto alunos mais entusiasmados pelas ciências naturais, quanto alunos mais interessados pelas ciências humanas e sociais.

Em 22 de agosto de 2019 foi realizada a primeira apresentação de divulgação científica sobre satélites artificiais para alunos de ensino médio de uma escola estadual situada no município de São Sebastião (Escola I). O título desta primeira apresentação foi "Física aeroespacial"; durante o seu transcorrer foi contextualizado historicamente o desenvolvimento de satélites artificiais e de foguetes, durante a corrida espacial entre EUA e URSS entre as décadas de 1950 e 1980. Nesta apresentação, foi realizada uma coleta de dados para pesquisa, com a aplicação junto aos presentes de um questionário A com algumas perguntas referentes à apresentação: 30 estudantes responderam este questionário A.

Em 27 de agosto de 2019 foi realizada essa mesma apresentação de divulgação científica intitulada "Física Aeroespacial" para alunos de ensino médio de uma escola estadual situada no município de Caraguatatuba (Escola II). Nesta apresentação, foram incluídos conhecimentos novos, tais como sobre a diferença entre sondas e satélites. Foi também explicado aos alunos um pouco a respeito da história das sondas Voyager 1 e 2 lançadas nos anos 1970 pelos Estados Unidos; para isso, foi apresentado aos estudantes a rica base de dados do site da NASA, que é atualizada a cada segundo, com informações históricas, científicas e tecnológicas sobre as sondas Voyager, inclusive sobre a distância de cada uma delas em relação a nós em cada instante $^{12}$. Também foi realizada uma coleta de dados para a pesquisa, com a aplicação do mesmo questionário A (já usado antes) junto aos alunos presentes, após o término da apresentação: 26 estudantes responderam este questionário A. Portanto, um total de 56 alunos de duas escolas (I e II) responderam este questionário A.

Em 17 de setembro de 2019, foi realizada novamente a apresentação de divulgação científica "Física Aeroespacial" para alunos de ensino médio de uma outra escola estadual situada no município de Caraguatatuba (Escola III). Nesta escola, a apresentação baseou-se naquela realizada no caso anterior, porém com um foco maior nas características científicas e tecnológicas dos satélites artificiais, como por exemplo acerca das suas órbitas, bem como sobre a presença brasileira no setor aeroespacial e acerca da importância das pesquisas nessa área para o desenvolvimento econômico e social das nações. Para explicar sobre o lixo espacial, foi

${ }^{12}$ Disponível em: https://voyager.jpl.nasa.gov/ 
utilizado um simulador existente na internet que mostra os objetos, produzidos pelo ser humano, que estão orbitando a Terra ${ }^{13}$.

Após esta apresentação também ocorreu uma nova coleta de dados, com a aplicação junto aos alunos de uma versão modificada do instrumento de pesquisa que denominaremos de questionário B, no qual foram incluídas algumas novas questões em relação ao questionário A aplicado nos dois casos anteriores, bem como foram excluídas algumas perguntas, para que este questionário B não ficasse muito extenso demandando um grande tempo para ser respondido: 30 estudantes responderam este questionário B. Esta mudança no instrumento de medida (o questionário) originou-se do fato de a apresentação de divulgação científica na escola III ter se alterado significativamente em relação àquela realizada nas duas escolas anteriores, o que levou à ideia de tentar mensurar as concepções dos alunos acerca de outras questões.

Em 24 de outubro de 2019, foi realizada uma apresentação de divulgação científica sobre tópicos de astronomia, física espacial e satélites artificiais, para alunos de ensino médio de uma escola estadual situada no município de Ubatuba (Escola IV). Com o título de "Da maçã à Lua", esta apresentação teve uma nova abordagem, focalizando outros temas, dentre eles: modelos astronômicos, as três leis de Kepler para o movimento planetário, a teoria da gravitação de Newton e a física do meio interplanetário.

Em 31 de outubro de 2019, foi realizada uma apresentação de divulgação científica sobre satélites artificiais e tópicos de astronomia e de física espacial, junto a alunos de ensino médio de uma outra escola estadual situada no município de Ubatuba (Escola V). Como o mesmo título da apresentação anterior ("Da maçã à Lua"), desta vez foram adicionados temas sobre a detecção de satélites artificiais e os principais perigos associados aos satélites artificiais.

Além dessas cinco apresentações de divulgação científica, em 22 de outubro de 2019, foi também realizada uma oficina educacional sobre a física envolvida no estudo dos satélites artificiais, durante a Semana Nacional de Ciência e Tecnologia (SNCT), do IFSPCaraguatatuba, que teve como público-alvo os alunos do curso de Licenciatura em Física do campus de Caraguatatuba do IFSP. Esta oficina permitiu analisar a forma como professores de física em formação compreendem os satélites artificiais tanto como objetos de conhecimento, quanto na condição de um eixo temático de suas futuras aulas para alunos da educação básica.

\footnotetext{
${ }^{13}$ Disponível em: http://stuffin.space/ 


\section{RESUltados E DISCUSSÃO}

As apresentações de divulgação científica estruturadas sobre o estudo de satélites e a física espacial ocorreram em cinco escolas públicas que foram visitadas entre agosto e outubro de 2019 e contemplaram conteúdos importantes a respeito de Física Espacial e Aeroespacial, Astronomia, Matemática e História da Ciência e da Tecnologia. Os seus impactos educacionais foram mensurados, em termos metodológicos, tanto por meio de observação atenta e dirigida em particular no que diz respeito às perguntas feitas pelos alunos e aos interesses científicos e históricos que eles revelaram possuir a partir das manifestações que realizaram -, quanto também pela aplicação de questionários. Dentre os temas tratados nas apresentações estavam a história da corrida espacial entre Estados Unidos e União Soviética, a diferença entre foguete, satélite e sonda espacial, as três leis de Kepler para os movimentos orbitais, a lei da gravitação universal de Newton, os diferentes tipos de satélites lançados ao espaço, a questão do lixo espacial e o desenvolvimento brasileiro na área espacial. O trabalho de contextualização permeado pela História da Ciência, em especial pela abordagem em torno da corrida espacial entre Estados Unidos e União Soviética, permitiu uma reflexão mais profunda sobre a importância do conhecimento científico e tecnológico e sobre como ele evolui com o tempo. Em todas as apresentações realizadas, os dois autores deste artigo estiveram presentes.

Em três das cinco apresentações realizadas, após a atividade, foi solicitado aos alunos presentes que respondessem um questionário com o intuito de investigar as concepções dos alunos acerca dos temas abordados: nas escolas I e II, 56 alunos responderam o mesmo questionário A (portanto, os dados foram agrupados), enquanto na escola III, 30 alunos responderam o questionário $\mathrm{B}$, sendo que no total, nas três escolas, foram obtidos 86 questionários respondidos. Cada questionário tinha cerca de 10 questões; os dois questionários (A e B) tinham perguntas em comum, mas apresentavam também algumas perguntas diferentes uma do outro. As duas perguntas iniciais (para caracterização do aluno que respondia o questionário) de todos os questionários eram sobre a idade e o gênero (masculino/feminino) de cada aluno. O Quadro 1 apresenta de forma sintética as questões presentes nos questionários A e B.

Quadro 1 - Questões presentes nos questionários A e B

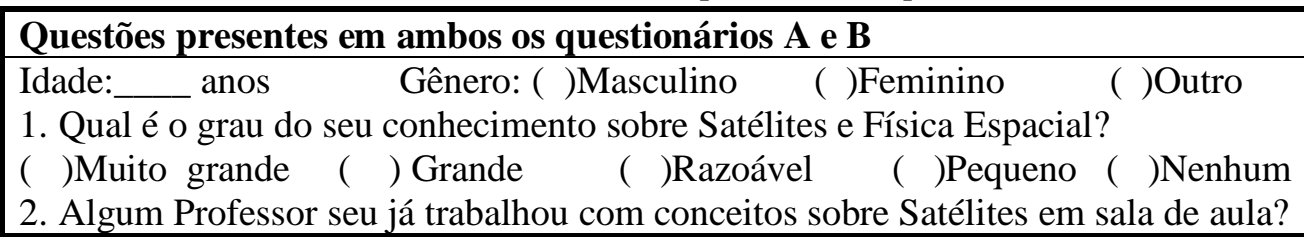


( )Não

( ) Sim - Qual disciplina?

3. Quanto a esta atividade da qual você participou, você conseguir compreender:

( )Tudo ou quase tudo ( )A maior parte ( )Pouco ( )Nada ou quase nada

4. Qual a chance de você seguir uma carreira em física, astronomia ou astronáutica?

$\begin{array}{lllll}\text { ( ) Muito grande ( )Grande ( )Razoável ( )Pequena } \quad \text { ( )Muito pequena } & \end{array}$

Questões presentes apenas no questionário $A$

A1. Você sabe onde no Brasil é possível estudar em cursos de Física Espacial e Astronomia?

( )Não

( ) Sim - Em qual cidade e instituição de ensino?

A2. Você sabe a diferença entre Satélites e Sondas Espaciais?

( )Não

( ) Sim - Qual a diferença:

A3. Você sabe qual foi o país que lançou o primeiro satélite a ir para o espaço?

( )Não

( ) Sim - Qual:

A4. Com as atuais naves que temos, quanto tempo você acha que duraria uma viagem de um foguete até a estrela mais próximo do sistema solar que é Alfa de Centauro? ____ anos

Questões presentes apenas no questionário B

B1. Você acha que o Brasil tem que fazer pesquisas em física espacial, foguetes e satélites?

( ) Sim ( )Não

Justifique:

B2. Você sabe se o Brasil tem alguma agência espacial que trata de satélites e foguetes?

( ) Sim ( )Não

B3. Você acha que um ser humano realmente já pisou e caminhou na Lua ou você acha que é tudo uma conspiração?

( )Um ser humano já pisou e caminhou na Lua

( )É tudo uma conspiração, pois nunca um homem foi para a Lua

B4. Qual você acha que é o principal motivo pelo qual pessoas defendem que a Terra é plana:

( )Porque a Terra de fato é plana

( )Porque eles querem aparecer e ganhar dinheiro com isso

( )Porque eles não têm conhecimentos científicos

( )Outro:

B5. Como você acha que seria a vida sem a existência de satélites artificiais?

Fonte: Elaborado pelos autores.

A seguir serão apresentadas as porcentagens de respostas em valores aproximados. Os alunos foram selecionados pelos gestores e professores das escolas visitadas que adotaram, como critério principal para essa escolha, a decisão de priorizar estudantes que tivessem previamente mostrado maiores interesses pelo estudo de disciplinas relacionadas às ciências naturais, em particular a física, mas também a química e a biologia. Este critério foi aceito, dentre outros motivos, porque os autores deste artigo - que planejaram e realizaram as apresentações - eram da comunidade externa ao ambiente escolar.

Quanto ao sexo, $56 \%$ dos alunos que responderam eram do gênero feminino, enquanto $44 \%$ eram do gênero masculino; este padrão de uma maioria de alunas nas atividades foi 
também observado com bastante nitidez nas outras atividades realizadas em que não foram aplicados questionários. Como os estudantes participantes foram selecionados pelos educadores da escola levando em consideração as suas afinidades com os temas científicos abordados nas apresentações, isto revela que muitas alunas apresentam, segundo os professores destas escolas, um interesse considerável pelo estudo de áreas científicas. Paradoxalmente, no âmbito universitário, os cursos de carreiras científicas em áreas como física contam com um corpo discente constituído majoritariamente por estudantes do gênero masculino, como ocorreu com o curso de Licenciatura em Física do IFSP-Caraguatatuba, em todas as quatro turmas que ingressaram anualmente entre 2017 e 2020, algo que acontece geralmente nos cursos de graduação em física de diferentes instituições universitários em todo o Brasil.

As razões pelas quais ocorre essa inversão do ensino médio para o ensino superior, "afugentando" potenciais alunas dos cursos de física - e de outros cursos associados às ciências exatas e às tecnologias - deveriam ser objeto de pesquisa, porque isto produz uma perda para o país, pois muitas jovens que poderiam estar colaborando com o desenvolvimento científico na área da física acabam decidindo-se por outras carreiras após terminarem o ensino médio.

Quanto às idades, 23\% dos estudantes tinham 15 anos de idade, 47\% tinham 16 anos, 23\% tinham 17 anos, 3\% tinham 18 anos e 3\% tinham 19 anos. Estas são idades típicas de alunos de ensino médio, que é a última etapa da formação correspondente à educação básica, durante a adolescência e em alguns casos começo da fase adulta.

Quatro perguntas estiveram presentes em todos os questionários (A e B) respondidos pelos 86 alunos: elas foram denominadas de questões 1, 2, 3 e 4 .

A questão 1 indagava o aluno sobre qual era o grau de conhecimento que eles tinham sobre satélites e física espacial: $2 \%$ dos alunos responderam muito grande, $2 \%$ grande, $37 \%$ razoável, $54 \%$ pequeno, $1 \%$ muito pequeno e $3 \%$ dos alunos se abstiveram, não respondendo esta questão. Estes dados evidenciam que mesmo alunos com maiores interesses por disciplinas científicas, como eram os alunos selecionados pelos seus professores para assistirem as apresentações de divulgação científica realizadas, não apresentavam muitos conhecimentos acerca de assuntos relacionados ao estudo de satélites e de física espacial, segundo eles mesmos.

A questão 2 indagava o aluno sobre se algum professor já tinha trabalhado com conceitos sobre satélites em sala de aula: $41 \%$ dos alunos responderam afirmativamente, enquanto $58 \%$ dos alunos responderam negativamente e $1 \%$ dos alunos se absteve ao não responder a esta questão. Estes dados sugerem que essa pode ser uma temática ainda pouco 
trabalhada em sala de aula. Um possível motivo pelo qual alguns professores não trabalhem com o estudo de satélites nas suas aulas, pode estar relacionado ao fato de que, durante a formação universitária pregressa, estes professores não tenham visto este gênero de assunto com a profundidade necessária para que eles se sintam seguros em planejar e realizar tarefas envolvendo-a; um outro possível motivo é que alguns professores talvez não encarem como importante trabalhar com este tipo de tema em sala de aula. Possivelmente são necessárias outras pesquisas para tirar uma conclusão mais segura a respeito. Para os alunos que responderam esta questão afirmativamente (um total de 35 alunos), 64\% deles afirmaram que isto aconteceu na disciplina de ciências (do ensino fundamental), 22\% afirmaram que isto aconteceu na disciplina de física, $8 \%$ afirmaram que isto aconteceu na disciplina de geografia e $6 \%$ afirmaram que isto ocorreu na disciplina de biologia. Portanto, estes dados indicam que a disciplina de física (que guarda grandes inter-relações com a área de estudo de satélites) tem aproveitado ainda relativamente pouco as possibilidades didáticas advindas da introdução do estudo de satélites em aulas do ensino médio: o caso mais óbvio dos benefícios de uma abordagem deste tipo é no estudo da mecânica clássica, muito utilizada na física espacial.

A questão 3 indagou o aluno sobre o quanto ele tinha compreendido na apresentação sobre satélites que eles assistiram: $23 \%$ dos alunos afirmaram que tinham compreendido "tudo ou quase tudo", 51\% afirmaram "a maior parte", 23\% afirmaram "pouco", 1\% respondeu "nada ou quase nada" e $1 \%$ se absteve. Portanto, do ponto de vista dos alunos, estes dados indicam que a apresentação realizada se mostrou estar em um nível razoavelmente compreensível.

A questão 4 indagava o aluno sobre qual era a probabilidade ou chance de ele no futuro seguir uma carreira profissional na área de física espacial, astronomia ou astronáutica: $9 \%$ dos alunos responderam que esta chance era "muito grande", 11\% responderam que era "grande", $23 \%$ responderam que era "razoável”, $23 \%$ responderam que era "pequena”, 33\% responderam que era muito pequena e $1 \%$ dos alunos se absteve de responder essa questão. Estes dados indicam que há uma parcela considerável de jovens de cerca de $43 \%$ que pensa ser pelo menos razoável a chance de seguirem no futuro uma carreira profissional em uma das três áreas mencionadas explicitamente na questão (física espacial, astronomia ou astronáutica), o que é algo significativo, pois aponta para o fato de que existem muitos jovens motivados para estas áreas, permitindo que, pelo menos hipoteticamente, exista a possibilidade de atrair quadros e se estruturar recursos humanos capacitados nesta área que é vital para o desenvolvimento do país. 
Vamos a seguir analisar o perfil de respostas dadas por 56 alunos para certas questões que eram exclusivas do questionário A (aplicado nas escolas I e II) e que não apareceram no questionário B. Para isto, vamos enumerar estas questões como sendo A-1, A-2, A-3, A-4.

A questão A-1 indagou o aluno sobre se ele sabia onde no Brasil era possível estudar em cursos superiores sobre Física Espacial e Astronomia: 32\% dos alunos responderam afirmativamente, enquanto $59 \%$ dos alunos responderam negativamente e $9 \%$ dos alunos se abstiveram. Isto indica um desconhecimento grande acerca de onde estudar (em nível superior) para se aperfeiçoar nas áreas de conhecimento abordadas na apresentação de divulgação científica feita sobre satélites artificiais. Solicitados para que escrevessem o nome da instituição ou do local onde é possível estudar nestes tipos de cursos superiores: 5 alunos responderam no IFSP-Caraguatatuba, 5 alunos responderam em São José dos Campos (onde estão situados o ITA e o INPE), 4 alunos responderam na cidade de São Paulo (onde está situada, por exemplo, a USP), 1 aluno respondeu o ITA, 1 aluno respondeu a USP e 1 aluno respondeu na cidade do Rio de Janeiro (onde, por exemplo, está situada a UFRJ).

A questão A-2 indagou o aluno sobre se ele sabia a diferença entre um satélite artificial e uma sonda espacial. Durante a apresentação tinha sido explicado aos presentes que um satélite artificial orbita um determinado corpo celeste, como, por exemplo, a Terra, enquanto uma sonda espacial é uma nave espacial não-tripulada utilizada para a exploração do espaço, em particular de outros planetas, satélites naturais ("luas"), asteroides ou cometas; na apresentação foram citadas como exemplos de sondas as duas naves Voyager 1 e 2. Para esta questão, 55\% dos alunos responderam afirmando que sabiam a diferença entre satélite artificial e sonda espacial, enquanto $38 \%$ dos alunos responderam negativamente e $7 \%$ dos alunos se abstiveram. A apresentação poderia ter enfatizado, portanto, de modo mais acentuado, a diferença existente entre satélites e sondas. Dentre algumas respostas dadas pelos alunos por escrito detalhando esta diferença podem ser destacadas as seguintes: "Sondas fazem pesquisas e satélites são como radar"; "O satélite é para ficar em volta de corpos celeste e sondas para coletar informações"; "Satélites ficam ao redor de algum corpo"; "Sondas são para analisar, satélites orbitam um planeta"; “As Sondas são para investigar o espaço e os satélites são para fotografar"; "Satélites orbitam sobre um corpo, já a sonda não”; “Os satélites orbitam, enquanto as sondas continuam viajando em frente"; "Sondas viajam, satélites orbitam"; "Satélites orbitam, sondas vão cada vez mais distante"; "Satélites ficam em órbita, agora as sondas são apenas lançadas no espaço sem rumo"; "Sondas são para exploração; satélites são feitas para pesquisa". 
A questão A-3 indagou o aluno sobre se ele sabia qual foi o primeiro país a lançar um satélite para o espaço: $84 \%$ dos alunos responderam afirmativamente, enquanto $16 \%$ dos alunos responderam negativamente. Aqueles que responderam afirmativamente foram solicitados que escrevessem o nome do país: 36\% dos alunos responderam "URSS" ("União das Repúblicas Socialistas Soviéticas" ou, simplesmente, "União Soviética"), 45\% responderam “Alemanha", 14\% responderam Rússia e 4 responderam "Sputnik". A confusão que muitos alunos parecem fazer entre União Soviética e Alemanha foi surpreendente, mas talvez esteja relacionada à influência difusa de obras cinematográficas e uma confusão relacionada ao fato de que ambas as nações em algum momento foram adversárias dos Estados Unidos: a Alemanha foi inimiga dos EUA durante a Segunda Guerra Mundial, enquanto a URSS foi inimiga dos EUA durante a Guerra Fria. A confusão existente acerca das diferenças entre nazismo e comunismo, exacerbada pelo processo de polarização política, pode também estar colaborando para isto.

A questão A-4 indagou o aluno sobre se ele tinha ideia de quanto tempo duraria, com as atuais naves espaciais, uma viagem espacial até a estrela mais próxima do Sol que é Alfa de Centauro. Durante a apresentação foi explicado que Alfa de Centauro está a aproximadamente 4 anos-luz de distância da Terra e foi feito um cálculo simples com uma estimativa de que a ordem de grandeza do tempo que duraria uma viagem até Alfa de Centauro, com as naves espaciais mais rápidas atuais que apresentam uma velocidade em relação à Terra da ordem de grandeza de $30 \mathrm{~km} / \mathrm{s}$, seria da ordem de 40 mil anos. Aproximadamente $39 \%$ dos alunos responderam que essa viagem duraria menos de mil anos, enquanto $23 \%$ responderam que demoraria entre mil e dez mil anos, $28 \%$ responderam que duraria entre dez mil e cem mil anos e $9 \%$ dos alunos se abstiveram. Portanto, a apresentação não foi suficiente para que muitos alunos tivessem a dimensão correta acerca da imensidão das distâncias interestelares (como é o caso da distância entre o Sol e a estrela mais próxima dele, que é Alfa de Centauro), quando consideradas pela perspectiva das velocidades atingidas pelas atuais espaçonaves.

Vamos agora analisar o perfil de respostas dadas por 30 alunos para certas questões que eram exclusivas do questionário B (aplicado na escola III) e que não apareceram no questionário A. Para isto, vamos enumerar estas questões como sendo B-1, B-2, B-3, B-4, B-5.

A questão B-1 indagou o aluno sobre se o Brasil deveria desenvolver pesquisas sobre física espacial, foguetes e satélites. Aproximadamente 93\% dos alunos responderam esta questão afirmativamente, contra $7 \%$ que responderam negativamente. Portanto, nesta amostra de estudantes parece estar claro para a esmagadora maioria que é fundamental que o Brasil 
desenvolva pesquisas nestas áreas do conhecimento, superando visões reducionistas, mas com um certo apelo popular, de que como o Brasil não é um país rico, não deveria "desperdiçar" recursos investindo em foguetes e satélites. Dentre as justificativas escritas fornecidas pelos que responderam afirmativamente, destacam-se: "Porque queremos saber mais sobre o assunto"; "Pois é importante ter conhecimento sobre essas coisas"; "Acho que o Brasil também tem poder para isso, então não deve ficar atrás"; "Todos países devem ter um certo conhecimento sobre isto"; "Sim, porque no Brasil tem pessoas capacitadas para isso"; "Para aprimorar o conhecimento"; "Pois há várias iniciativas para satélites"; "Sempre é bom para a evolução de nosso país"; "É algo interessante que pode até motivar muitas pessoas que querem seguir carreira nessa área".

A questão B-2 indagou o aluno sobre se ele sabia dizer se o Brasil tem alguma agência espacial que trata especificamente de satélites e foguetes: $73 \%$ dos alunos responderam afirmativamente, contra $27 \%$ dos alunos que responderam negativamente. A apresentação realizada conferiu um certo destaque para o trabalho realizado pela AEB - Agência Espacial Brasileira $^{14}$, mas pelo resultado, uma parcela apreciável dos alunos presentes (27\%) não entendeu a importância desta agência.

A questão B-3 indagou o aluno sobre se ele achava que realmente um ser humano já tinha pisado e caminhado na Lua (tema este que foi abordado na apresentação) ou se ele achava que tudo não passava de uma conspiração: $77 \%$ dos alunos responderam que achavam que o homem já tinha de fato pisado na Lua, enquanto $20 \%$ dos alunos afirmaram que tratava-se uma conspiração a ideia de que um ser humano já caminhou na superfície da Lua e 3\% dos alunos se abstiveram. Pode ser considerado preocupante o fato de que um quinto dos alunos defendem teorias da conspiração anedóticas e sem quaisquer evidências factuais ou experimentais. Podemos nos interrogar sobre o quanto estes alunos que defenderam a ideia de uma conspiração sobre a viagem do homem à Lua acreditam realmente nisso ou responderam deste modo apenas para chamar a atenção ou parecerem engraçados, mas o fato é que as mais bizarras teorias da conspiração têm ganhado bastante força nos últimos anos e este crescimento guarda uma relação muito grande com a forma como os divulgadores destas teorias da conspiração usam as redes sociais e as ferramentas da internet para disseminar suas crenças.

A questão B-4 indagou o aluno acerca de qual seria o principal motivo, na opinião deles, para o fato de algumas pessoas acreditarem que a Terra seja plana. Uma maioria de $60 \%$ dos

\footnotetext{
${ }^{14}$ Disponível em: https://www.gov.br/aeb/pt-br
} 
alunos respondeu que isto acontecia devido ao fato de estas pessoas não terem conhecimentos científicos, enquanto $20 \%$ deles afirmaram que estas pessoas querem aparecer ou ganhar dinheiro com isto e $17 \%$ alegaram outros motivos. Um único aluno (3\%) respondeu dizendo que isto ocorria porque a Terra era de fato plana. $\mathrm{O}$ fato de termos um aluno terraplanista poderia ser apenas um deboche ou uma piada por parte dele, sobretudo sabendo que os alunos não se identificavam ao responderem o questionário e mantinham-se no anonimato. De qualquer modo, é importante lembrar que uma pesquisa realizada em 2019, entrevistando 2.086 pessoas, revelou que $7 \%$ dos brasileiros são terraplanistas e, portanto, têm a crença de que a Terra é um disco plano e não uma esfera aproximada (GARCIA, 2019).

A questão B-5 era aberta e indagou os alunos sobre como eles achavam que seria a vida dos seres humanos sem a existência de satélites artificiais. Os alunos responderam esta questão com um texto escrito; vamos reproduzir a seguir algumas das respostas sobre como eles pensam que seria a vida sem satélites artificiais:

- "Com algumas dificuldades, sem comunicação";

- "Com mais dificuldade em nosso dia a dia, sem informação";

- "Ficaria sem internet";

- "Não teríamos tecnologia";

- "Sem internet, sem comunicação a distância";

- "Seria bastante complicado, porque não teríamos, comunicação alguma e seria horrível sem celular";

- "Seria diferente, mas se não se conhecesse o satélite, seria normal";

- "Seria bem ignorante";

- "Seria monótono, como nos anos em que eles não existiram, é só olhar um pouquinho para trás";

- "Seria sem conhecimento científico";

- "Seria muito chato, talvez nem existiria a tecnologia";

- "Um atraso tecnológico, que nos impediria e dificultaria a realização de diversas atividades".

É possível perceber que os alunos conferem uma importância muito grande nas vidas deles para a existência do celular e da internet, que para vários não existiriam sem satélites artificiais.

As respostas dadas pelos alunos às perguntas dos questionários traçam um panorama das concepções existentes nas suas mentes sobre temas relacionados ao estudo dos satélites 
artificiais: isto é útil a professores, pois para se obter uma aprendizagem significativa e eficaz, é fundamental a identificação dos conhecimentos prévios dos alunos acerca de um determinado assunto que devem servir como ponto de partida para as ações educacionais (MOREIRA, 2011).

\section{CONSIDERAÇÕES FINAIS}

As apresentações de divulgação científica de caráter audiovisual, sobre a física espacial e o estudo de satélites artificiais, foguetes e sondas, que foram planejadas e realizadas, durante o transcorrer desta pesquisa, procuraram ter uma linguagem mais acessível para os alunos do ensino médio. O uso de recursos disponíveis na internet - como simulações, vídeos de curta duração, fotografias, infográficos etc. - mostrou que há uma grande diversidade de ferramentas que os professores podem utilizar tanto para motivar os alunos, quanto para colaborar nas explicações acerca de alguns conceitos científicos abordados.

Em particular, o trabalho de contextualização possibilitado pela História da Ciência e da Tecnologia permitiu abordar junto aos alunos o modo pelo qual conhecimentos científicos e tecnológicos são produzidos pelo esforço coletivo da humanidade e evoluem com o tempo. Em particular, mostrou-se rico em termos pedagógicos abordar tanto a respeito da ciência e da história da corrida espacial entre Estados Unidos e União Soviética no século XX, quanto a respeito das consequências econômicas e sociais decorrentes do desenvolvimento de pesquisas no setor aeroespacial, por parte de diferentes nações, nos dias de hoje, inclusive pelo Brasil.

Relacionar o passado com a atualidade é, frequentemente, uma boa possibilidade de estratégia para analisar como o estudo da história da ciência pode ajudar a entender os dilemas e desafios científicos dos dias de hoje. Neste sentido, o vídeo "China vai conquistar a Lua", com duração de cerca de 7 minutos e que está disponível no canal "Ciência e Café"15, da plataforma de armazenamento de vídeos Youtube, pode ser um recurso útil, em ações educacionais, para evidenciar que assim como no século XX ocorreu uma corrida espacial entre EUA e URSS, atualmente também está em curso uma nova corrida espacial, dessa vez entre Estados Unidos e China.

O estabelecimento de interrelações entre o passado histórico e as demandas da atualidade evidencia como o desenvolvimento científico e tecnológico é um elemento estratégico para qualquer nação, inclusive para o Brasil, e, portanto, mostra a importância de investir recursos humanos e financeiros em pesquisas no setor espacial e em diversificar as parcerias com outros países, na busca por atingir a fronteira científica e tecnológica que é hoje

\footnotetext{
${ }^{15}$ Disponível em: https://www.youtube.com/watch?v=wYorNOdwcPA
} 
- como sempre foi, anteriormente, ao longo da história - onde mais se agrega valor econômico que pode redundar em melhores condições de vida e mais bem estar social para a população em geral. Além disso, para que a apresentação de divulgação científica planejada pudesse apresentar um quadro mais panorâmico foram utilizados, também, conhecimentos de outras áreas, como astronomia, matemática, física, eletrônica e informática.

Durante o segundo semestre de 2019, apresentações de divulgação científica sobre o estudo de satélites foram realizadas em cinco momentos diferentes para alunos de ensino médios de escolas estaduais localizadas em municípios do litoral norte paulista: os impactos educacionais destas atividades foram positivos como revelaram não somente as respostas dos estudantes aos questionários aplicados, mas também os comentários e observações que eles fizeram durante as atividades, bem como como alguns relatos feitos pelos seus professores após a realização das atividades. Além disso, a identificação dos conhecimentos prévios dos alunos sobre a área da física espacial apontada por esta pesquisa pode fornecer elementos que colaborem para trabalhos futuros de outros educadores sobre esta temática.

Ocorreu uma presença maior de alunas, de modo sistemático, em todas as apresentações, o que revela que estudantes adolescentes do gênero feminino apresentam um grau de motivação grande para estudar em cursos universitários relacionados às ciências exatas (como física e matemática) e às tecnologias (como computação), cursos estes que paradoxalmente contam com um corpo discente mais acentuadamente masculino: é importante envidar esforços e realizar pesquisas para procurar compreender melhor os motivos pelos quais este cenário parece se inverter do ensino médio para o ensino superior. O estímulo à curiosidade científica e o incentivo de jovens talentosos, de ambos os gêneros, para carreiras profissionais das áreas citadas anteriormente é importante para a captação de recursos humanos que são vitais para o desenvolvimento econômico, social e tecnológico do país.

\section{REFERÊNCIAS}

ALBAGLI, Sarita; CLINIO, Anne; RAYCHTOCK, Sabryna. Ciência Aberta: correntes interpretativas e tipos de ação. Liinc em Revista, v. 10, n. 2, p. 434-450, nov. 2014. Disponível em: http://revista.ibict.br/liinc/article/view/3593. Acesso em: 18 mar. 2021.

ALBAGLI, Sarita. Divulgação científica: informação científica para cidadania. Ciência da Informação, v. 25, n. 3, p. 396-404, set./dez. 1996. Disponível em: http://revista.ibict.br/ciinf/article/view/639. Acesso em: 19 mar. 2021. 
CAIN, Fraser. How Many Satellites are in Space? Universe Today. 2013. Disponível em: https://www.universetoday.com/42198/how-many-satellites-in-space/. Acesso em: 17 mar. 2021.

CARLEIAL, Aydano Barreto. Uma Breve História da Conquista Espacial. Parcerias Estratégicas, v. 4, n. 7, 1999. Disponível em:

http://seer.cgee.org.br/index.php/parcerias estrategicas/article/view/78. Acesso em: 17 mar. 2021.

CHAIKIN, Andrew. A man on the Moon. Penguin, 2019.

COSTA, Bárbara Sigilião. Projeto de uma plataforma científica que simula as características e a operação de um pico-satélite para promover a educação em ciências e tecnologias aeroespaciais. Brasília, DF: Projeto de Graduação - UnB, 2013. Disponível em: https://bdm.unb.br/handle/10483/6043. Acesso em: 18 mar. 2021.

DIVINE, Robert Alexander. The Sputnik Challenge. New York, U.S.A.: Oxford University Press, 1993.

GARCIA, Mark. 60 years ago: The First Animal in Orbit. NASA. 2017. Disponível em: https://www.nasa.gov/feature/60-years-ago-the-first-animal-in-orbit. Acesso em: 18 mar. 2021.

GARCIA, Rafael. 7\% dos brasileiros afirmam que Terra é plana, diz pesquisa. 15 de julho de 2019. Disponível em: https://gauchazh.clicrbs.com.br/tecnologia/noticia/2019/07/7dos-brasileiros-afirmam-que-terra-e-plana-diz-pesquisa-cjy4n2vac01s901njeelvoimp.html. Acesso em: 20 mar. 2021.

GOMES, Emerson Ferreira; PIASSI, Luís Paulo de Carvalho. Corrida Espacial, Mídia e Rock n'Roll: A Exploração Espacial em seu Contexto Midiático e sua Representação na Cultura Pop. Resumos do XXXVII Congresso Brasileiro de Ciências da Comunicação- Intercom, Foz do Iguaçu, PR. 2014. Disponível em: http://www.intercom.org.br/sis/2014/resumos/R92276-1.pdf. Acesso em: 18 mar. 2021.

HARARI, Yuval Noah. 21 lições para o século 21. São Paulo: Companhia das Letras, 2018.

HOWELL, Elizabeth. What is a Satellite? Space. 2017. Disponível em:

https://www.space.com/24839-satellites.html. Acesso em 3 jan. 2021.

LAVANDER, Andrew. How many satellites are orbiting the Earth in 2020? Pixalytics, 27 de maio de 2020. Disponível em: https://www.pixalytics.com/satellites-orbiting-earth-2020/. Acesso em: 19 mar. 2021.

MAGALHÃES, Cíntia; SILVA, Evanilda da; GONÇALVES, Carolina. A interface entre alfabetização científica e divulgação científica. Revista Areté - Revista Amazônica de Ensino de Ciências, v. 5, n. 9, p. 14-28, 2017. Disponível em http://periodicos.uea.edu.br/index.php/arete/article/view/44. Acesso em: 19 mar. 2021.

MAY, Sandra. Who Was Alan Shepard? NASA. 2017. Disponível em: https://www.nasa.gov/audience/forstudents/k-4/stories/nasa-knows/who-was-alan-shepardk4.html. Acesso: 17 mar. 2021. 
MOREIRA, Marco Antonio. Aprendizagem Significativa: a teoria e textos complementares. São Paulo: Livraria da Física, 2011.

NEAL, Homer A.; SMITH, Tobin L.; MCCORMICK, Jennifer B. Beyond Sputnik: U.S. Science Policy in the Twenty-First Century. Ann Arbor, U.S.A.: University of Michigan, 2008 .

OLIVEIRA, Graziele Lopes de. Panorama das pesquisas sobre divulgação científica / popularização da ciência no Brasil. Rio Grande (RS): Dissertação de Mestrado (Universidade Federal do Rio Grande), 2015. Disponível em: <https://sistemas.furg.br/sistemas/sab/arquivos/bdtd/0000010810.pdf>. Acesso em: 21 mai. 2021.

PESSOA FILHO, José Bezerra. O contexto histórico da corrida espacial. $1^{\text {a }}$ Jornada Espacial, São José dos Campos, SP, 2005. Disponível em:

https://educacaoespacial.files.wordpress.com/2010/10/ijespacial_03_corrida_espacial_p1.pdf. Acesso em: 16 mar. 2021.

REIS, Norma Teresinha Oliveira et al. Análise da dinâmica de rotação de um satélite artificial: uma oficina pedagógica em educação espacial. Revista Brasileira de Ensino de Física, v. 30, n. 1, 1401, 2008. Disponível em http://dx.doi.org/10.1590/S180611172008000100011. Acesso: 18 mar. 2021.

SANTOS, Wildson Luiz Pereira dos; MORTIMER, Eduardo Fleury. Uma análise de pressupostos teóricos da abordagem C-T-S (Ciência-tecnologia-Sociedade) no contexto da educação brasileira. Revista Ensaio, v. 2, n. 2, p.110-132, 2002. Disponível em: https://doi.org/10.1590/1983-21172000020202. Acesso em: 19 mar. 2021.

SILVA, Luciano Fernandes; CARVALHO, Luiz Marcelo de. Professores de física em formação inicial: o ensino de física, a abordagem CTS e os temas controversos. Investigações em Ensino de Ciências, v. 14, n. 1, p. 135-148, 2009. Disponível em:

https://www.if.ufrgs.br/cref/ojs/index.php/ienci/article/view/414/246. Acesso em: 19 mar. 2021.

THE ROYAL SOCIETY. Final report - Science as an open enterprise. 21 june 2012.

Disponível em: https://royalsociety.org/topics-policy/projects/science-publicenterprise/Report/. Acesso em: 15 mar. 2021.

WILLIAMS, David R. Luna 1. NASA. 2019. Disponível em:

https://nssdc.gsfc.nasa.gov/nmc/spacecraft/display.action?id=1959-012A. Acesso em: 18 mar. 2021.

WINTER, Othon Cabo; PRADO; Antonio Fernando Bertachini de Almeida. A Conquista do Espaço: do Sputnik à Missão Centenário. São Paulo: Editora Livraria da Física, 2007.

\section{Agradecimentos}

Agradecemos ao CNPq pelo financiamento desta pesquisa. 